\title{
Andreas Sohn, Jacques Verger, Michel Zink (éds.), Heinrich Denifle (1844-1905). Un savant dominicain entre Graz, Rome et Paris
}

Paris, Académie des Inscriptions/Belles-Lettres, 2015, 301 p.

\section{Alain Rauwel}

\section{(2) OpenEdition \\ Journals}

Édition électronique

URL : http://journals.openedition.org/assr/28341

DOI : 10.4000/assr.28341

ISSN : $1777-5825$

\section{Éditeur}

Éditions de l'EHESS

\section{Édition imprimée}

Date de publication : 31 décembre 2016

Pagination : 387

ISSN : 0335-5985

\section{Référence électronique}

Alain Rauwel, « Andreas Sohn, Jacques Verger, Michel Zink (éds.), Heinrich Denifle (1844-1905). Un savant dominicain entre Graz, Rome et Paris ", Archives de sciences sociales des religions [En ligne], 176 | octobre-décembre 2016, mis en ligne le 20 juillet 2017, consulté le 24 septembre 2020. URL : http://journals.openedition.org/assr/28341 ; DOI : https://doi.org/10.4000/assr.28341

Ce document a été généré automatiquement le 24 septembre 2020

(C) Archives de sciences sociales des religions 


\section{Andreas Sohn, Jacques Verger, Michel Zink (éds.), Heinrich Denifle (1844-1905). Un savant dominicain entre Graz, Rome et Paris}

Paris, Académie des Inscriptions/Belles-Lettres, 2015, 301 p.

\section{Alain Rauwel}

\section{RÉFÉRENCE}

Andreas Sohn, Jacques Verger, Michel Zink (éds.), Heinrich Denifle (1844-1905). Un savant dominicain entre Graz, Rome et Paris, Paris, Académie des Inscriptions/BellesLettres, 2015, $301 \mathrm{p}$.

Rien n'importe plus au chercheur en sciences sociales que de déterminer les circonstances et les motivations qui ont présidé à la construction des objets d'étude devenus canoniques en son domaine. Et on sait bien que le $\mathrm{XIX}^{\mathrm{e}}$ siècle, temps de révolution industrielle, a été aussi une prodigieuse forge de concepts, de notions, de formules qui scandent (et parfois empoisonnent) notre réflexion. Il y avait donc mille raisons de se pencher sur le cas d'Heinrich Denifle, historien dominicain célèbre à la fin $\mathrm{du} \mathrm{XIX}^{\mathrm{e}}$ et au début du XXe siècle, dont les éditions et monographies ont puissamment contribué à donner leur faciès moderne à plusieurs champs de recherche très fréquentés: la mystique médiévale, les origines des universités, la "guerre de Cent Ans » (une formule assez malheureuse qui doit beaucoup à Denifle, comme le montre Jean-Marie Moeglin dans l'une des bonnes études du volume), la Réforme. Le colloque tenu à Paris en décembre 2012 et dont l'Académie des Inscriptions et Belles-Lettres a assuré l'édition ne donnera cependant que peu de grain à moudre à l'amateur d'historiographie. Les origines populaires et tyroliennes de Denifle sont décrites de manière purement annalistique, sans la vaste remise en contexte qui s'imposait. La 
dimension dominicaine, à savoir le développement de l'intérêt pour l'histoire dans un ordre de tradition spéculative, est ramenée à une notule bibliographique. Les positions théologiques et ecclésiologiques du savant, que l'on entrevoit par allusions, ne sont pas étudiées systématiquement, alors qu'elles conditionnent évidemment l'orientation de ses travaux. En réalité, les médiévistes français engagés dans ce colloque derrière Jacques Verger se sont surtout intéressés au grand Chartularium Universitatis Parisiensis, dans une perspective avant tout archivistique et documentaire. Si une bonne communication de Volker Leppin montre bien ce que signifiait envisager l'œuvre latine d'un mystique allemand dans le monde germanique d'après le Kulturkampf, la frustration atteint son maximum à propos de l'œuvre la plus influente de Denifle, qui est aussi sa dernière contribution au débat historique : le Luther und Luthertum de 1904, grande œuvre de polémique et en même temps pierre miliaire des études luthériennes, dont l'influence s'est étendue dans toute l'Europe et sur plusieurs décennies (elle a "secoué la somnolence des luthérologues", disait Paul Vignaux). L'évocation en est sommaire. On n'y rencontre même pas le nom de Lucien Febvre, dont tout le début du Martin Luther de 1927 est une explication avec Denifle, ni celui de Maritain, dont les Trois réformateurs de 1925 sont, comme l'a montré Michel Deneken, à la remorque du dominicain. Les éditeurs du colloque parisien de 2012 n'ont pas eu tort de choisir pour illustration de couverture un Denifle de bronze : c'est un personnage statufié qu'ils célèbrent plus qu'un savant vivant, résolument engagé dans les combats idéologiques d'une époque ardente. Leur Vita beati Denifli laisse place à un autre livre, à venir, qui pourra être, selon la jolie formule de Richard Southern, a portrait in a landscape. 